\title{
Development of a Physics Laboratory Activity Kit for the Do-It-Yourself (DIY) Physics Equipment and Laboratory Activity
}

\author{
Submitted 3 June 2021 Revised 31 January 2022 Accepted 31 January 2022 \\ Elesar V. Malicoban ${ }^{1 *}$, Ellen J. Castro ${ }^{2}$ \\ ${ }^{1,2}$ Department of Science and Mathematics Education, College of Education, \\ MSU-Iligan Institute of Technology, Iligan City, Philippines \\ Corresponding Email: *elesar.malicoban@g.msuiit.edu.ph
}

\begin{abstract}
The main objective of this study was to develop a Physics laboratory activity kit for the Do-It-Yourself (DIY) Physics equipment and laboratory activity to be used in Physics classes of high school students. The resulting kit was assessed by the selected pre-service and in-service Physics teachers. This study employed a mixed methods. Assessment of the laboratory activity kit which includes the Student Worksheets, Teacher's Guide, and Equipment Construction was done by the in-service and pre-service Physics teachers in order to ensure a workable DIY Physics equipment and quality laboratory activity kit which shall be of great use in Physics class. The pre-service and in-service rated the Student Worksheet as very good. The DIY Physics equipment was workable. The laboratory activity for the DIY Physics equipment was appropriate for the fourth-year students. The Teacher's Guide in the laboratory activity kit was very good and can guide the teacher on what to do before, during, and after the activity. The Equipment Construction was very good and appropriate for the teacher's guide and laboratory activity.
\end{abstract}

Keywords: Laboratory activity kit, Student worksheets, Teacher's guide, Equipment construction

\section{INTRODUCTION}

According to many studies, teacher's teaching methods or approaches can affect students' learning. Ely (2012) and Muema et al (2018) found that teaching methods have correlation to students' performance. Hence, it needs to carefully design learning process using the appropite teaching methods (Santos \& Boyon, 2020).

According to Bernardo (2004), the poor preparation of science teachers and the inadequate science curriculum give effects to the poor performance of learners in the primary school. Additionally, (Tupas \& Matsuura, 2011) found that the scarcity of instructional materials can become an effect of low performance of students.

According to the study of Orleans (2007), Philippine secondary schools, particularly in physics, need to develop instructional media such as print materials non-print materials. This can be deduced that high quality of educational materials is lacking and insufficient. This should be given immediate response as it is necessary in order for the teachers to ensure excellent delivery of instruction in the field.

This study was conducted based on the following objectives: (1) Develop a Physics laboratory activity kit to utilize the DIY Physics equipment and laboratory activity; (2) Assess the readability of the Physics laboratory activity kit; and (3) Assess the Physics laboratory 
International Journal of STEM Education for Sustainability, Vol 2, No.2, 2022, pp. 172-179

e-ISSN 2798-5091. DOI. 10.53889/ijses.v2i2.7

activity kit by the pre-service and in-service Physics teachers.

\section{METHOD}

This research employed mixed methods. Creswell and Plano Clark (2011) define mixedmethods research as those studies that include at least one quantitative strand and one qualitative strand. Rating sheets, which were based on the rubric made by Jarantilla (2008), were used to assess the workability of the Teacher's Guide, Student Worksheet, and Equipment Construction of the laboratory activity kit. Assessment on the teacher's guide was done in terms of its references, skills, concepts, strategy, answers to questions, application, layout, and spelling and grammar. Assessment on the student worksheet was done in terms of its title, introduction, objectives, materials, procedure, questions, layout, spelling and grammar, and time allotment. Assessment on the equipment construction was done in terms of its equipment name, concepts involved, tools, code, preparation of materials, procedure, assembly, layout, and spelling and grammar. To test the readability of the laboratory activity kit, the Flesch-Kincaid test and cloze test were used.

The organization of the content of the laboratory activity kit was based on the construction manual developed by the DepEd-NSTIC. Since the Looping Track was the chosen apparatus, the researcher focused on the format provided by the manual on the Looping Track. The laboratory activity kit was developed consisting mainly of the Student Worksheet, Teacher's Guide, and Equipment Construction. The Student Worksheet contained the procedure of the activity intended for the students while the Teacher's Guide was designed to provide teachers the details on how to handle the laboratory activity. The Equipment Construction showed the name of the equipment, the concepts involved, the tools and materials needed, procedure, and the assembly of the equipment with the exploded view and isometric view. The laboratory activity kit included an illustration for the necessary concept which was the transformation of energy demonstrated in the activity using the enhanced DIY Physics equipment.

A tryout was conducted to assess the workability of the laboratory activity kit. It was attended by selected students, pre-service Physics teachers, and in-service Physics teachers. During the tryout, the researcher did the pre-laboratory session to discuss the concepts involved using the enhanced DIY Physics equipment and to prepare the materials that are needed in the laboratory activity. The students were provided with the worksheet individually, during the laboratory activity and enough time was given to record their observations and to answer the questions in the activity. During the conduct of the activity, the researcher noted the flaws of the designed activity for corrections and improvement. The researcher did the post-laboratory discussion to check the answers of the students in the activity. 
International Journal of STEM Education for Sustainability, Vol 2, No.2, 2022, pp. 172-179 e-ISSN 2798-5091. DOI. 10.53889/ijses.v2i2.7

\section{RESULTS AND DISCUSSION}

I. Development of the Physics Laboratory Activity Kit

Input

\begin{tabular}{|l|}
\hline \\
Designing the \\
Physics Activity \\
Kit \\
- Student \\
Worksheet \\
- Teacher's Guide \\
- Equipment \\
Construction \\
\hline
\end{tabular}

Process

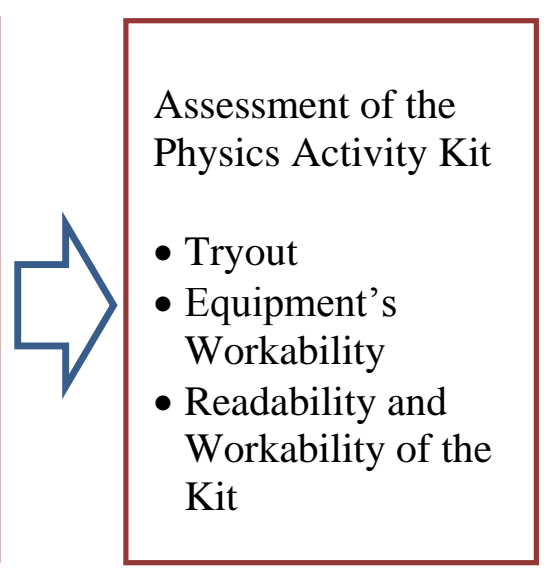

Output

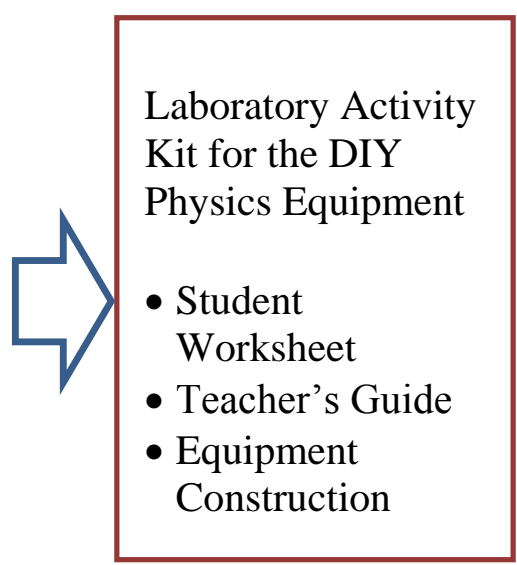

Figure 1. Stages of Development of the Physics Activity Kit

Figure 1 shows that in the conduct of the study, the development of Physics laboratory activity kit was based on the findings of modification of the DIY Physics equipment and enhancement of the improvised DIY Physics equipment, of which a laboratory activity was designed. Findings on the assessment of the enhanced DIY Physics equipment and designed laboratory activity were utilized for the development of the Physics laboratory activity kit.

A tryout was conducted for the assessment of the laboratory activity kit which includes the Student Worksheets, Teacher's Guide, and Equipment Construction. The assessment was done by the in-service and pre-service Physics teachers in order to ensure a workable DIY Physics equipment and quality laboratory activity kit which shall be of great use in Physics class. The physics laboratory aids the students to establish a relevance theory that brings clarity in the mind of the learners regarding the concepts being taught (Ndihokubwayo et al., 2018).

The modified the DIY differential radioscope was developed by Metante (2012). Additionally, using the improvised laboratory device, Buot (2010) developed and evaluated a laboratory apparatus that would help teach several topics in magnetism. 
International Journal of STEM Education for Sustainability, Vol 2, No.2, 2022, pp. 172-179 e-ISSN 2798-5091. DOI. 10.53889/ijses.v2i2.7

II. Assessment on the Readability of the Physics Laboratory Activity Kit

Table 1. Assessment on the Readability of the Physics Laboratory Activity Kit Using FleschKincaid Test

\begin{tabular}{lcl}
\hline \multicolumn{1}{c}{ Parts of the Kit } & Score & Interpretation \\
\hline Preface & 42.8 & Best understood by university graduates \\
Teacher's Guide overview & 42.2 & Best understood by university graduates \\
Laboratory activity overview & 25.5 & Best understood by university graduates \\
Equipment construction & 35.9 & Best understood by university graduates \\
$\quad$ overview & 55.1 & Best understood by university graduates \\
Teacher's guide & 71.9 & Easily understood by 13-15 year-old \\
Laboratory activity & 52.6 & Best understood by university graduates \\
Equipment construction &
\end{tabular}

Based on the Table 1, the result revealed that the laboratory activity kit was intended for in-service Physics teachers while the laboratory activity was intended for students in Grades 79.

With the use of a cloze test, the assessment on the readability of the laboratory activity was revealed. The table below shows the result of the cloze test administered among five (5) fourth year students.

Table 2. Assessment on the Readability of the Physics Laboratory Activity Kit using Cloze Test

\begin{tabular}{cccc}
\hline Student & Score & Percentage & Interpretation \\
\hline 1 & 10 & 100 & Independent level \\
2 & 10 & 100 & Independent level \\
3 & 10 & 100 & Independent level \\
4 & 10 & 100 & Independent level \\
5 & 9 & 90 & Independent level \\
\hline
\end{tabular}

Based on the Table 2, the result revealed that the five (5) fourth year students belonged to the independent level, which implies that all the students recognized most of the words and content of the laboratory activity.

Results of the assessment of the readability of the laboratory activity kit encompassed the goal of the K-12 curriculum program. The aim of the K-12 Curriculum is to produce productive and responsible learners equipped with the essential competencies and skills for both lifelong learning and employment (K to 12 Curriculum Guide Science, 2016). However, problems arise as the new curriculum has been implemented. According to the study of Rivera (2017), the newly implemented curriculum still has loopholes especially in the articulation of pedagogical approach to learner-centeredness.

III. Assessment on the Physics Laboratory Activity Kit

Rating sheets were used to assess the workability of the Teacher's Guide, Student Worksheet, and Equipment Construction of the laboratory activity kit. 
International Journal of STEM Education for Sustainability, Vol 2, No.2, 2022, pp. 172-179 e-ISSN 2798-5091. DOI. 10.53889/ijses.v2i2.7

Table 3. Assessment on the Teacher's Guide

\begin{tabular}{|c|c|c|c|c|}
\hline \multirow{2}{*}{ Criteria } & \multicolumn{2}{|c|}{ Pre-Service Physics } & \multicolumn{2}{|c|}{ In-Service Physics } \\
\hline & Mean Rating & Interpretation & Mean Rating & Interpretation \\
\hline References & 3.71 & Very good & 3.92 & Very good \\
\hline Skills & 3.83 & Very good & 3.65 & Very good \\
\hline Concepts & 3.71 & Very good & 3.69 & Very good \\
\hline Strategy & 3.93 & Very good & 3.75 & Very good \\
\hline $\begin{array}{r}\text { Answers to } \\
\text { questions }\end{array}$ & 3.81 & Very good & 3.50 & Very good \\
\hline Application & 3.57 & Very good & 3.25 & Good \\
\hline Layout & 3.82 & Very good & 3.69 & Very good \\
\hline $\begin{array}{l}\text { Spelling and } \\
\text { grammar }\end{array}$ & 3.64 & Very good & 3.50 & Very good \\
\hline Overall mean & 3.75 & Very good & 3.62 & Very good \\
\hline
\end{tabular}

Legend: 1.00-1.74 (poor), 1.75-2.49 (fair), 2.50-3.24 (good), 3.25-4.00 (very good)

Based on the Table 3, the assessment of the pre-service Physics teachers on the Teacher's Guide, the Teacher's Guide had the highest mean rating in terms of its strategy because the participants found out that the strategy was simple and clearly stated, led to the attainment of objectives, guided the teacher on what to do before, during, and after the activity. The suggested activity was doable. The Teacher's Guide had the lowest mean rating in terms of its application because for the participants, the concept was not clearly observed in the application.

Based on the assessment of the in-service Physics teachers on the Teacher's Guide, the highest mean rating was given to its references because the participants observed that the references were reliable, clearly stated, and properly identified. The Teacher's Guide had the lowest mean rating in terms of its application because for the participants the concept was not clearly stated in the application. They suggested using the term "losing" when it pertains to transformation of energy, rather than saying "giving up".

The overall assessment on the Teacher's Guide was very good for pre-service and inservice Physics teachers. However, one (1) pre-service Physics teacher suggested including textbooks for references. The in-service Physics teachers suggested including the idea of the conservation of mechanical energy and to add one objective for the activity, which is to cite the application of the conservation of mechanical energy.

The physics laboratory aids the students to establish a relevance theory that brings clarity in the mind of the learners regarding the concepts being taught. The leaners will understand the difference between theory and application. The absence of these materials in teaching physics could to low performance (Ndihokubwayo et al., 2018). According to Bernardo (2004), the poor preparation of science teachers and the inadequate science curriculum give effects to the poor performance of learners in the primary school. Additionally, (Tupas \& Matsuura, 2011) found 
International Journal of STEM Education for Sustainability, Vol 2, No.2, 2022, pp. 172-179 e-ISSN 2798-5091. DOI. 10.53889/ijses.v2i2.7

that the scarcity of instructional materials can become an effect of low performance of students. Table 4. Assessment on the Equipment Construction

\begin{tabular}{lcccc}
\hline \multirow{2}{*}{ Criteria } & \multicolumn{2}{c}{ Pre-Service Physics } & \multicolumn{2}{c}{ In-Service Physics } \\
& Mean Rating & Interpretation & Mean Rating & Interpretation \\
\hline Equipment name & 4.00 & Very good & 3.75 & Very good \\
Concepts involved & 3.76 & Very good & 4.00 & Very good \\
Tools & 3.76 & Very good & 3.92 & Very good \\
Code & 3.86 & Very good & 3.75 & Very good \\
Preparation of & 3.76 & Very good & 3.92 & Very good \\
$\quad$ materials & 3.82 & Very good & 4.00 & Very good \\
Procedure & 3.79 & Very good & 3.88 & Very good \\
Assembly & 3.96 & Very good & 3.88 & Very good \\
Layout & Spelling and & Very good & 3.75 & Very good \\
$\quad$ grammar & 4.00 & Very good & 3.87 & Very good \\
\hline Overall mean & 3.86 & Led
\end{tabular}

Legend: 1.00-1.74 (poor), 1.75-2.49 (fair), 2.50-3.24 (good), 3.25-4.00 (very good)

Based on the Table 4, the assessment of the pre-service Physics teachers on the Equipment Construction, the highest mean rating was in terms of its equipment name because the name given was simple and clearly stated. It also had the highest mean rating in terms of its spelling and grammar because the participants did not find any misspelled words or grammatical errors. The equipment construction had the lowest mean rating in terms of the concepts involved because the concept was not so clearly stated, not brief and concise, and not very appropriate for the age, year level, and maturity of the students.

Based on the assessment of the in-service Physics teachers on the Equipment Construction, the equipment construction had the highest mean rating in terms of the concepts involved because for the participants the concept was clearly stated, brief and concise, and appropriate for the age, year level, and maturity of the students. The equipment construction had a low mean rating in terms of its equipment name because for the participants the equipment name was not simple and clearly stated. The equipment construction also had a low mean rating in terms of its code because the participants found that the codes were not brief and concise, not simple and clearly stated. The equipment construction also had a low mean rating in terms of its spelling and grammar due to a few grammatical errors.

The overall assessment on the equipment construction was very good for pre-service and in-service Physics teachers. Results further revealed that the assessment on the DIY Physics equipment, laboratory activity, teacher's guide, and equipment construction done by the inservice Physics teachers was based on their experiences in teaching Physics. The suggestions they had given reflected the way they picture out Physics in the class.Many fundamental 
experiments require pieces of equipment that are very overweening commercially. The lack of budget of public schools is one of the challenges that the government is trying to resolve (Malonzo \& Fajardo, 2017). The teacher will be challenged on how he will give a meaningful lesson that the learners will appreciate and understand. Developing an apparatus is novelty by utilizing economical and functional equipment envisioned to help learners appreciate underlying physics principles through experiments. It will give the teacher the opportunity to deliver the lesson in a more interactive way unlike from traditional teaching strategies (Fatubarin, 2001).

\section{CONCLUSION}

The DIY Physics equipment was workable. The laboratory activity for the DIY Physics equipment was appropriate for the fourth-year students. The teacher's guide in the laboratory activity kit was very good and can guide the teacher on what to do before, during, and after the activity. The equipment construction was very good and appropriate for the teacher's guide and laboratory activity.

\section{REFERENCES}

Aina, K. J. (2013). Instructional materials and improvisation in physics class: Implications for teaching and learning. Computer, 2(20), 8.

Bernardo, A. B. I. (2004). Constructivism, curriculum and the challenges in transforming science education in the Philippines. Learning Edge, 4, 1-33.

Buot, K. (2010). Development and Evaluation of a Demonstration Kit on Faraday's Law and Lenz's Law (Master's Thesis). College of Education, MSU-Iligan Institute of Technology.

Creswell, J.W. and Plano Clark, V.L. (2011) Designing and Conducting Mixed Methods Research. 2nd Edition, Sage Publications, Los Angeles.

Ely, A. (2012). Teaching Strategies to Improve Student Perceptions of Academic Success: An Approach toward Immediacy. EWU Masters Thesis Collection.

Fatubarin, A. (2001). The challenge of improvisation in science teaching in the present day Nigeria. Journal of committee of Provosts of colleges of Education, Nigeria, 1(1), 92.

Jarantilla, E. (2008). Development of Laboratory Activity Manual for the Do-It-Yourself (DIY) Chemistry Equipment (Master's Thesis). College of Education, MSU-Iligan Institute of Technology.

K to 12 Curriculum Guide Science (2016) Retrieved from http://www.deped.gov.ph/wpcontent/uploads/2019/01/Science-CG_with-tagged-sci-equipment_revised.pdf \

Malonzo, C., \& Fajardo, M. (2017). Design and Evaluation of Demonstration Tools for Newton's Laws of Motion. American Journal of Educational Research, 5(2), 155-160. 
Metante, M. (2012). Modification of a Do-It-Yourself (DIY) Differential Radioscope Apparatus (Undergraduate Thesis). College of Education, MSU-Iligan Institute of Technology.

Mohammad, N. K. (2016). The perception of the parents and students on the implementation of $\mathrm{K}-12$ basic education program in the Philippines. In International Conference on Education (IECO) FKIP Unmuh Jember (Vol. 1, No. 1).

Muema, J., Mulwa, D., \& Mailu, S. (2018). Relationship between teaching method and students' performance in Mathematics in public secondary schools in Dadaab Sub County, Garissa County; Kenya. IOSR Journal of Research \& Method in Education, 8(5), 59-63.

Ndihokubwayo, K., Uwamahoro, J., \& Ndayambaje, I. (2018). Use of improvised experiment materials to improve Teacher Training College students' achievements in Physics, Rwanda. African Journal of Educational Studies in Mathematics and Sciences, 14, 71-84.

Orleans, A. V. (2007). The condition of secondary school physics education in the Philippines: Recent developments and remaining challenges for substantive improvements. The Australian educational researcher, 34(1), 33-54.

Rivera, J. G. (2017). Articulating the foundations of Philippine K to 12 curriculum: learnercenteredness. AsTEN Journal of Teacher Education, 2(1).

Santos, J. C., \& Boyon, M. (2020). Effect of Inquiry-based Lessons on STEM Students' Learning Competencies on Limits and Continuity. PEOPLE: International Journal of Social Sciences.

Tupas, F. P., \& Matsuura, T. (2011). Comparative studies of science education curricula between Japan and the Philippines. The Journal of the School Education Society of Hakodate, 16, 13-22. 